\title{
Risk Assessment on Diabetic Peripheral Neuropathy from a Cohort of Patients in China
}

\author{
Xueyan Liu\#, Fangting Ma\#, Jiewei Huang, Xiaoyu Chen, Minna Zhang, Junlan Yan, Qingling \\ Chen,Jiao Du, Pei Li, Peiru Zhou* and Jiaying Li* \\ Department of Endocrinology, The First Affiliated Hospital of Jinan University, China

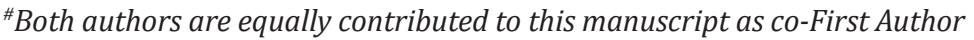

*Corresponding author: Jiaying Li, Peiru Zhou, The first affiliated Hospital of Jinan University, No. 613, Huangpu Avenue West, Tianhe District, Guangzhou City, Guangdong Province 510630, China

\begin{tabular}{|c|c|}
\hline ARTICLE INFO & Abstract \\
\hline Received:蔧 May 18, 2020 & The objective of this study was to screen out some hallmarks from diabetic patients \\
\hline Published: May 27, 2020 & $\begin{array}{l}\text { with diabetic peripheral neuropathy (DPN), and conduct some risk assessment } \\
\text { on these hallmarks so that diagnosis and intervention can be taken earlier to stop } \\
\text { the irreversible process. Total } 933 \text { patients were enrolled, and a prospective cross- }\end{array}$ \\
\hline $\begin{array}{l}\text { Citation: Xueyan L, Fangting M, Jiewei H, } \\
\text { Peiru Z, Jiaying L, et al., Risk Assessment } \\
\text { on Diabetic Peripheral Neuropathy from a } \\
\text { Cohort of Patients in China. Biomed J Sci \& } \\
\text { Tech Res 27(5)-2020. BJSTR. MS.ID.004573. }\end{array}$ & $\begin{array}{l}\text { sectional study method was employed to analyze clinical signs and manifestations } \\
\text { that were examined based on guidelines recommended by The American Diabetes } \\
\text { Association (ADA) and the Chinese Medical Association of Diabetes Society (CMADS). } \\
\text { Those screen and diagnostic methods included (1) Sense of touch (10g monofilament } \\
\text { (Nylon) test); (2) Sense of vibration (128 Hz tuning fork vibration to measure the } \\
\text { vibration perception threshold (VPT)); (3) Temperature discrimination; (4) Pinprick }\end{array}$ \\
\hline $\begin{array}{l}\text { Abbreviation: T2DM, Type } 2 \text { diabetes } \\
\text { Mellitus; DPN: Diabetic Peripheral Neu- } \\
\text { ropathy; T1DM: Type } 1 \text { Diabetic Mellitus; }\end{array}$ & $\begin{array}{l}\text { (a } 40 \mathrm{~g} \text { pin to touch); (5) Tendon reflex. The diagnosis of DPN falls into the criteria from } \\
\text { the preventive guidelines of Chinese Type } 2 \text { Diabetes Mellitus (T2DM) (2017 Version). } \\
\text { The results indicated type } 2 \text { diabetes mellitus was } 96.5 \% \text {, and the incidence of DPN was } \\
43.7 \% \text { among T2DM. }\end{array}$ \\
\hline
\end{tabular}
ing Blood Glucose; HDL: High Density Lipoprotein; LDL: Low Density Lipoprotein; DFU: Diabetic Foot Ulcer; TG: Triglycerides. TC: Cholesterol; VPT: Vibration Perception Threshold; CPT: Electric Current Perception Threshold; ABI: Ankle-Brachial Index; BMI: Body Mass Index; SNCT: Sensory Nerve Conduction Threshold; PAD: Diabetic Peripheral Vascular Disease

The prevalent risk factors were higher in DPN than non-DPN with statistical significance, which included the elder $(>45 \mathrm{Y})(\mathrm{P}<0.01)$, the lower educational levels $(\mathrm{P}<0.01)$, the longer duration of T2DM $(>5 \mathrm{Y})(\mathrm{P}<0.01)$, with diabetic retinopathy $(\mathrm{P}<0.01)$, with diabetic kidney $(\mathrm{P}<0.05)$, with diabetic antipathy of lower extremity $(\mathrm{P}<0.05)$, with diabetic foot ulcer $(\mathrm{DFU})(\mathrm{P}<0.05$ and callus (right and left foot) $(\mathrm{P}<0.05)$, abnormal sensation (numbness of right and left foot) $(\mathrm{P}<0.01)$ the abnormal vibration sense (right foot) $(\mathrm{P}<0.05)$, the abnormal temperature sense (right foot) $(\mathrm{P}<0.05)$, missing or disappearing Nylon pressure sense (right and left) $(\mathrm{P}<0.05)$, abnormal VPT (right and left) $(\mathrm{P}<0.01)$ and abnormal CPT (right and left feet) $(\mathrm{P}<0.05)$. Our study predicts some risk factors including elder patients with longer 5 years diabetes mellitus, with diabetic retinopathy, diabetic kidney, angiopathy of lower extremity, plus foot ulcer or callus, and abnormal physical signs through five golden standard screening methods, should be alerted for clinicians to be cautious about diabetic peripheral neuropathy.

Keywords: Diabetes Mellitus; Diabetic Peripheral Neuropathy; Risk Factor

\section{Introduction}

Human living styles and life has been troubled by diabetes for many decades that arises from 451 million patients (ages from 18-99 years) worldwide in 2017. Approximately 85-95 of patients are diagnosed with T2DM in developed countries, and higher proportion in developing countries, which is emerged as an imminent global health crisis [1-5]. In China, the incidence of T2DM reached at $10.4 \%$ in 2013 , and twice was arisen from fat population. However, un-diagnosed diabetes or threshold diabetes of a large population is an imperative threat that is looming ahead. About $30-50 \%$ diabetes is developed and ailed with Diabetic Peripheral Neuropathy (DPN) sooner or later [2]. DPN is one of 
the major progressive complications of diabetes mellitus, which is continuously assaulted by hyperglycemia and aggravated by high risk factors, and is defined as the presence of peripheral nerve dysfunction in diabetics after exclusion of other causes. However, those high-risk factors may be varied upon different demographic features and T2DM development. Human DPN is characterized by nerve fiber loss, axonal degeneration, and segmental demyelization with a decrease in nerve conduction velocity due to decreased intraepidermal nerve fiber density and reduced myelin thickness of the nerve sheath, so DPN is one of the most insidious, asymptomatic complications of diabetes, but it could results in irreversible foot ulcer, insensate foot injury, lower-extremity amputation and mortality in diabetic patients [6-8].

In addition, DPN dramatically change patients' life style, adding heavy economic burdens. Therefore, it is imperative screening out high-risk factors of DPN be conducted to predict DPN for earlier diagnosis and save patients' foot and lives. The American Diabetes Association (ADA) recommends the following screening tests for early diagnosis of DPN: 1) Pinprick; 2) Sense of temperature; 3) Sense of vibration; 4) Sense of touch (10g monofilament (Nylon) test) [8]. The Chinese Medical Association of Diabetes Society Advocates recommends both screening tests and clinical symptoms be combined [2]. Our hospital has been always underscoring screening standards of DPN based on accumulation of continuous practical experience and insights into DPN since 2016 by virtue of the screening standards of the Diabetes Branch of Chinese Medical Association. The present study summarized total 933 cases from December 2018 to December 2019 and conducted analysis by a prospective cross-sectional study method, and provided some valuable results for sharing with peers in order to predict the occurrence of DPN for early diagnosis.

\section{Subjects}

Participants were selected and enrolled in this the study, the inclusion criteria were: (1) diagnosed diabetes patients according to diagnostic criteria for diabetes from the World Health Organization in 1999; (2) acceptance of this study procedure; (3) capable of communication freely; (4) free movement of four limbs with Muscle Strength at Grade 4 or beyond. Written consent was obtained from every participant. The exclusion criteria were: (1) unable to communicate verbally; (2) hemiplegic patients and nondiabetic patients; (3) neuropathies elicited by other causes, such as cervical and lumbar lesions nerve root compression, spinal stenos is, cervical and lumbar degeneration, cerebral infarction, GuillainBarré Syndrome, Serious arteriovenous diseases like venous embolism, lymphangitis, etc.

\section{Research Method}

A prospective cross-sectional study was employed to collect clinical data. According to the inclusion criteria above, the diabetic patients who were admitted to the Department of Endocrinology of the First Affiliated Hospital of Jinan University from December
2018 to December 2019 were selected therein. Using systemic random sampling technique to recruit participants who met the inclusion criteria every 20th patient file was taken, and patient was interviewed and examined until the minimal sample size was reached.

\section{Clinical Repertoire}

A standard questionnaire of demographic data as sex, age, categorized educational levels, duration of diabetes, and Lab results including cholesterol, triglyceride, Glycated hemoglobin, ABI, BMI, medication, plus questioning complaints about numbness, pain, itching, and other symptoms of the lower extremities were available or not.

\section{Clinical Tests}

According to previous studies and guidance $[9,10]$, the clinical specialist for performing tests received professional training and earned a certificate to complete the screening tests independently. The clinical tests should be performed in a quiet environment, and the participant should close his/her eyes when being tested and then recognize the perception of the pressure or pin stick at right site (indicated in (Figures $1 \mathrm{~A}-1 \mathrm{H}$ ). These clinical tests were depicted as below

Sense of Touch: Using 10G Nylon monofilament to pressure the standard 10 points as shown in (Figures $1 \mathrm{E} \& 1 \mathrm{G}$ ). The contact time was 2 seconds with interval of 2-3 seconds between sites. Perception of 10 points is defined as "normal", but loss of 2 or more of 10 points' perception was defined as "weaker", and loss of 10 points' perception was defined as "missing."

Sense of Vibration: $128 \mathrm{~Hz}$ tuning fork vibration test was used by a sensor meter-VPT made by Beijing Lanxun Times Technology Company, and the scale of the vibrator was $0-8 \mathrm{~s}$. The tuning fork was placed on the surface of the first metacarpal joint of the foot toe. The amplitude of vibration was progressively increased from zero to a barely detectable vibration amplitude (threshold) at which the patient was just able to sense the vibration. The best cutoff value was proven to $10.54 \mathrm{~V}$. Thresholds between 0 to 10 volts were considered normal, 11-15 volts slightly abnormal (threshold), 16-25 volts moderately abnormal, and $>25$ volts severely abnormal.

Temperature Discrimination: The temperature stick was placed on the dorsum of the foot to exam the temperature discrimination. Patients were instructed to lie back, close their eyes, and relax, and then were asked to determine if the temperature stick touched to the back of their feet felt warm or cool. An inability to distinguish cool from warm was considered an "abnormal" test result.

Pinpricking Pain (Needle Tingling Test): The examiner uses a 40 -g pin to touch the abdomen of the patient's first, third and fifth toes. Patients who did not feel being touched in any position are considered an "abnormal" result. 


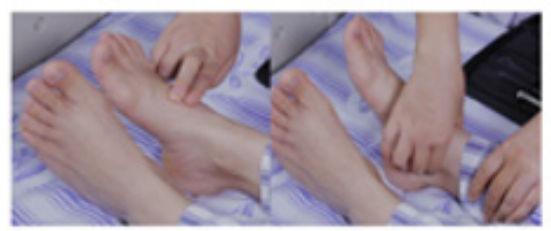

(4)

$\left(\frac{10}{20}\right.$

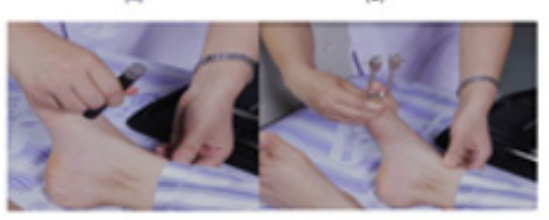

이
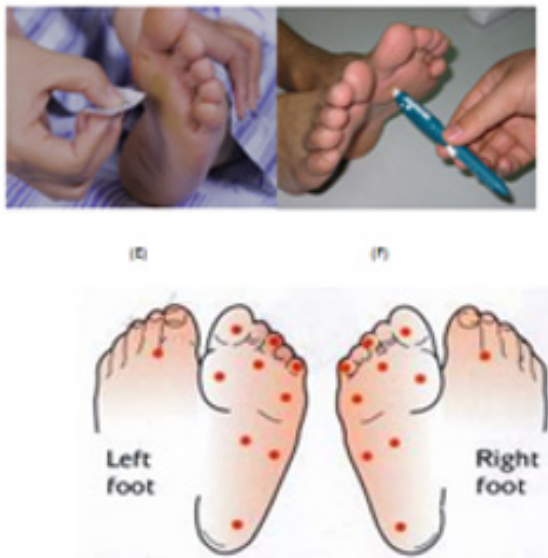

(6)
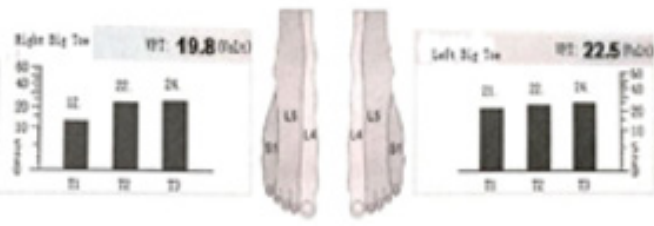

Figure 1: Illustration of physical exams for DPN.

A. Palpation of dorsal plantar artery

B. Palpation of posterior tibial artery

C. Sense of temperature

D. Sense of vibration

E. Sense of touch(10g Nylon needle)

F. Pinpricking pain(40gneedle)

G. Positions and locations of touch and pinpricking on feet.

H. Locations and thresholds of VPT.

Tendon Reflex: The patient was directed to take the supine position, one knee flexion at 90 degrees after the natural prolapse abduction. A percussion hammer was used to gently tap the quadriceps femoris tendon (knee reflex) and calcaneus tendon (ankle reflex) with moderate strength. The results of muscle contraction and plantar flexion were assessed aseither present or absent and then compared.

The diagnostic criteria of DPN is based on the Chinese guidelines for the prevention and treatment of Type 2 diabetes (2017 edition) [2], with reference to the diagnostic method proposed by the
American Diabetic Association [2,8]. First, the patient has been diagnosed with diabetes. Secondly, the neuropathies caused by other diseases should be excluded. Finally, five physical exams should be positive:

1. There are clinical symptoms (pain, numbness, etc.), and any one of the five tests (pressure, vibration, needle pain, temperature, and ankle reflexes) is abnormal and will be diagnosed DPN;

2. Though without significant clinical symptoms, any two of the five tests are abnormal and will be diagnosed DPN;

3. Vibration perception threshold test (VPT): More than 15 volts;

4. CPT: Quantitative measurement of sensory nerve (Neurotron's Neurometer CPT / CYZB / USA3886-2013): determine the sensory nerve conduction threshold (SNCT) of the superficial peroneal and deep peroneal nerves of the lower extremities by measuring the current perception threshold (CPT) of the skin / mucous membrane of the thumb. This is a rapid and painless test to objectively and fairly analyze and quantify the function of sensory nerve fibers with or without myelin sheath. The severity of neuropathy will be classified from 0 to 12 grades. "0" grade was set up as normal.

5. Peripheral vascular diagnostic system (Vista AVS from Summit Doppler systems company, USA): patients were instructed into a supine position, and $12 \mathrm{~cm}$ x $40 \mathrm{~cm}$ deflated cuffs were separately placed on both ankle and upper arms. Doppler stethoscope was used to measure the systolic pressure of the dorsal is pedis artery, the posterior tibial artery and brachial artery. The ankle-brachial Index (ABI) is the ratio of the pressure of the dorsal is pedis artery or the posterior tibial artery (whichever is higher) to the pressure of the brachial artery. The ankle-brachial Index (ABI) is useful for early diagnosis and screening of Diabetic Peripheral Vascular Disease (PAD). The sensitivity of PAD is $95 \%$ when $\mathrm{ABI} \leq 0.9$. The range of ankle-brachial index was 0.91-1.39 in normal subjects.

\section{Statistical Analysis}

SPSS19.0 software was used for statistical analysis. The quantitative data were expressed as \pm and statistical differences were conducted byt test used between groups. The counting data were expressed as an example number (percentage)[ $\mathrm{n}(\%)]$ and Chi-square test ( $\mathrm{X} 2$ ) was used to analyze the risk factors of peripheral neuropathy, the level of test was 0.10 , the cut-off value was 0.15 , and the difference was statistically significant $(\mathrm{p}<0.05)$.

\section{Results}

\section{Effect of Demographic Profile and Clinical Symptoms on Diagnosis of DPN}

A total of 1000 patients with diabetes were included in this study, of which 67 patients who lost some data were excluded. 
As shown in (Table 1), there were 933 effective cases collected in this study, including 511 males and 422 females. The mean age was $(58.72 \pm 14.43)$ years, and the mean duration of disease was $(8.36 \pm 7.47)$ years. There were 901 cases of T2DM, 24 cases of T1DM and 8 cases of special type diabetes. DPN394 cases, non-DPN 539 cases. The incidence of DPN was $42.2 \%$. As shown in (Figure 2), if factors of DPN and Non-DPN were put together in parallel, the four highest percentages of incidence or factors were put in order: Age $(>40 \mathrm{Y})>$ Duration $(10 \mathrm{Y})>$ Education level $>$ Diabetic retinopathy. However, if risk factors of DPN were subtracted by those of Non-DPN, the four highest percentages of incidence or factors were put in order: Diabetic retinopathy > Duration (10Y) > Diabetic angiopathy of low extremity $>$ Diabetic kidney. These four risk factors were closely associated with the occurrence of DPN (Figure 3).

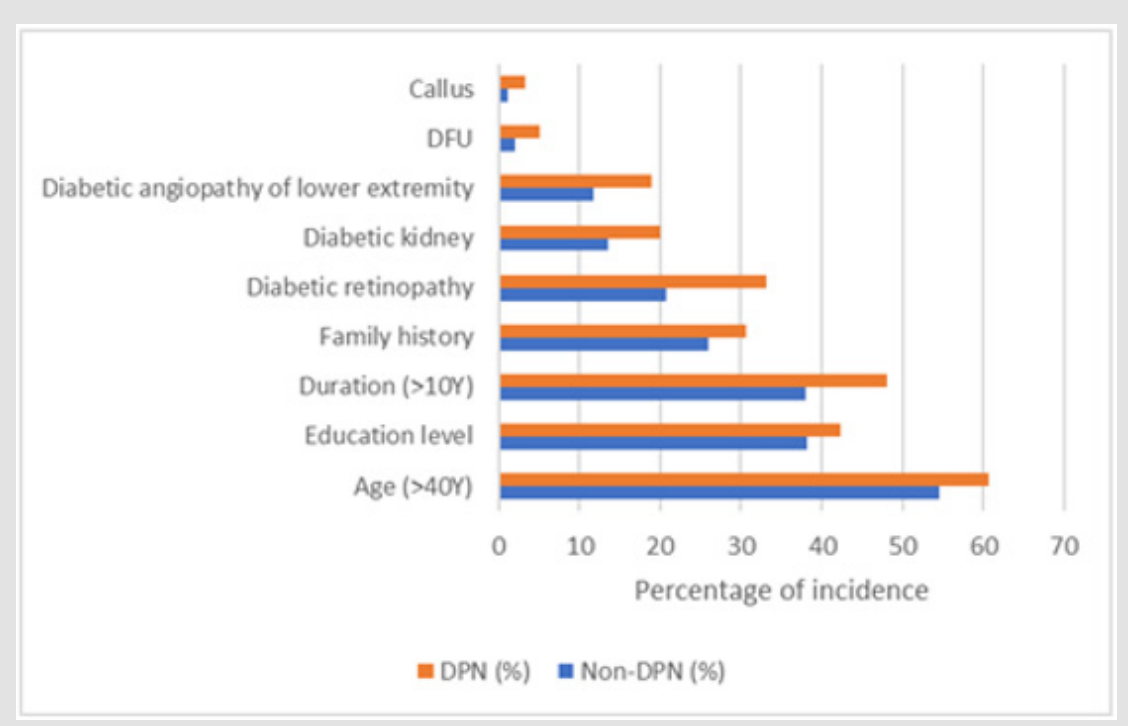

Figure 2: Comparison of demographic factors and clinical symptoms between DPN and Non-DPN ( $\mathrm{n}=933)$.

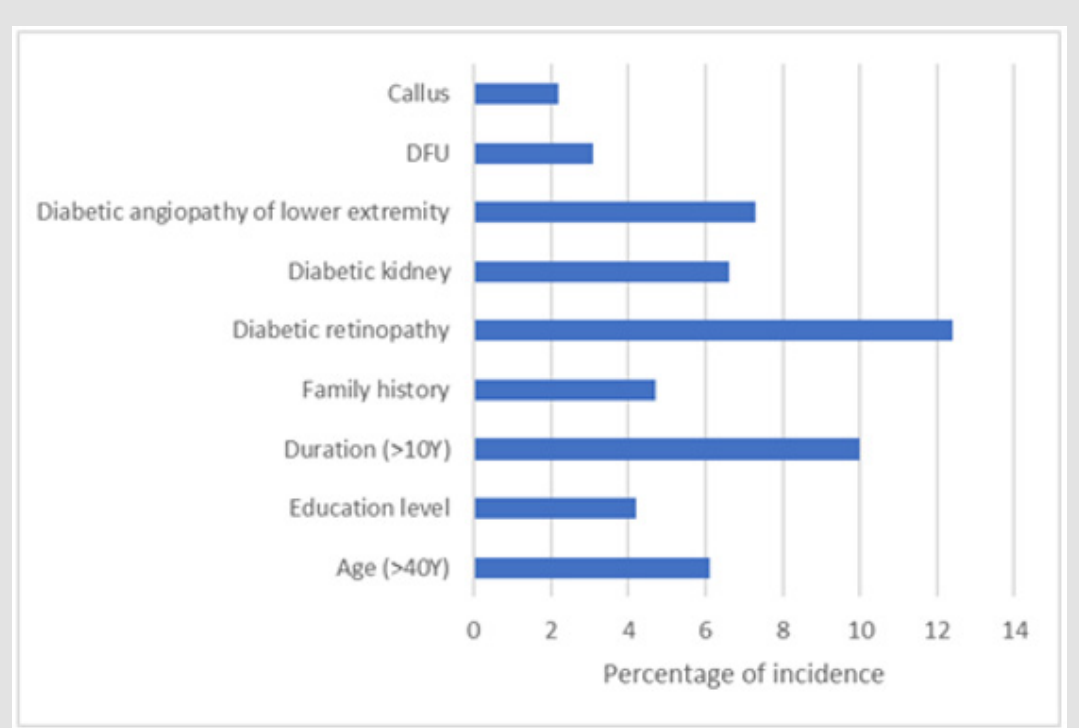

Figure 3: Net of demographic factors and clinical symptoms by DPN minus Non-DPN ( $\mathrm{n}=933)$.

Table 1: Risk factors of demographic features, physical signs and clinical symptoms between DPN and non-DPN. (n=933).

\begin{tabular}{|c|c|c|c|}
\hline Risk factors & No DPN(n=539) $(\mathbf{\%})$ & $\begin{array}{c}\text { DPN(n=394) } \\
(\mathbf{\%})\end{array}$ & $\boldsymbol{P}^{\mathbf{1}}$ \\
\hline Sexuality & & $201(51)$ & 0.049 \\
Male,n(\%) & $310(57.5)$ & $193(49)$ & \\
Female,n(\%) & $229(42.5)$ & \\
\hline
\end{tabular}




\begin{tabular}{|c|c|c|c|}
\hline $\begin{array}{c}\text { Age } \\
<41 \text { years old,n(\%) } \\
41 \sim 65 \text { years old,n(\%) } \\
\geq 66 \text { years old,n(\%) }\end{array}$ & $\begin{array}{ll}79 & (14.7) \\
294 & (54.5) \\
166 & (30.8)\end{array}$ & $\begin{aligned} 23 & (5.8) \\
239 & (60.7) \\
132 & (33.5)\end{aligned}$ & 0.001 \\
\hline $\begin{array}{c}\text { Educational level } \\
\text { Illiteracy,n(\%) } \\
\text { primary school,n(\%) } \\
\text { secondary school,n(\%) } \\
\text { junior college or above,n(\%) }\end{array}$ & $\begin{array}{cc}17 & (3.2) \\
155 & (28.8) \\
206 & (38.2) \\
161 & (29.9)\end{array}$ & $\begin{aligned} 32 & (8.1) \\
124 & (31.5) \\
167 & (42.4) \\
71 & (18.0)\end{aligned}$ & 0.000 \\
\hline $\begin{array}{c}\text { Marriage } \\
\text { Single,n(\%) } \\
\text { Married,n(\%) }\end{array}$ & $\begin{aligned} 15 & (2.8) \\
524 & (97.2)\end{aligned}$ & $\begin{array}{cc}3 & (0.8) \\
391 & (98.2)\end{array}$ & 0.001 \\
\hline $\begin{array}{c}\text { duration of disease (year) } \\
\qquad \begin{array}{c}<\text {,n(\%) } \\
5-10, \mathrm{n}(\%) \\
\geq 10, \mathrm{n}(\%)\end{array}\end{array}$ & $\begin{array}{ll}238 & (44.2) \\
96 & (17.8) \\
205 & (38.0)\end{array}$ & $\begin{array}{ll}122 & (31.0) \\
83 & (21.1) \\
189 & (48.0)\end{array}$ & 0.000 \\
\hline $\begin{array}{c}\text { Family history } \\
\text { No,n(\%) } \\
\text { Yes,n(\%) }\end{array}$ & $\begin{array}{l}404(75.0) \\
135(25.0)\end{array}$ & $\begin{array}{ll}273 & (69.3) \\
121 & (30.7)\end{array}$ & 0.055 \\
\hline $\begin{array}{l}\text { Smoking } \\
\text { No,n(\%) } \\
\text { Yes,n(\%) }\end{array}$ & $\begin{array}{l}427(79.2) \\
112(20.8)\end{array}$ & $\begin{array}{l}310(78.7) \\
84(21.3)\end{array}$ & 0.841 \\
\hline $\begin{array}{c}\text { Diabetic retinopathy } \\
\text { No,n(\%) } \\
\text { Yes,n(\%) }\end{array}$ & $\begin{array}{l}427(79.2) \\
112(20.8)\end{array}$ & $\begin{array}{ll}263 & (66.8) \\
131 & (33.2)\end{array}$ & 0.000 \\
\hline $\begin{array}{l}\text { Diabetic Kidney } \\
\text { No,n(\%) } \\
\text { Yes,n(\%) }\end{array}$ & $\begin{array}{l}466(86.5) \\
73(13.5)\end{array}$ & $\begin{array}{l}315(79.9) \\
79(20.1)\end{array}$ & 0.008 \\
\hline $\begin{array}{l}\text { Diabetic angiopathy of lower extrer } \\
\qquad \begin{array}{c}\text { No, } \mathrm{n}(\%) \\
\text { Yes,n(\%) }\end{array}\end{array}$ & $\begin{array}{l}476(88.3) \\
63(11.7)\end{array}$ & $\begin{array}{l}319(81.0) \\
75(19.0)\end{array}$ & 0.002 \\
\hline $\begin{array}{c}\text { DFU } \\
\text { No,n(\%) } \\
\text { Yes,n(\%) }\end{array}$ & $\begin{array}{c}528(98.0) \\
11(2.0)\end{array}$ & $\begin{array}{cc}374 & (94.9) \\
20 & (5.1)\end{array}$ & 0.011 \\
\hline $\begin{array}{c}\text { Callus (left) } \\
\text { No,n(\%) } \\
\text { Yes,n(\%) }\end{array}$ & $\begin{array}{c}532(98.7) \\
7(1.3)\end{array}$ & $\begin{array}{c}380(96.4) \\
14(3.6)\end{array}$ & 0.022 \\
\hline $\begin{array}{c}\text { Callus (right) } \\
\text { No, n(\%) } \\
\text { Yes,n(\%) }\end{array}$ & $\begin{array}{c}534(99.1) \\
5(0.9)\end{array}$ & $\begin{array}{c}382(97.0) \\
12(3.0)\end{array}$ & 0.017 \\
\hline
\end{tabular}




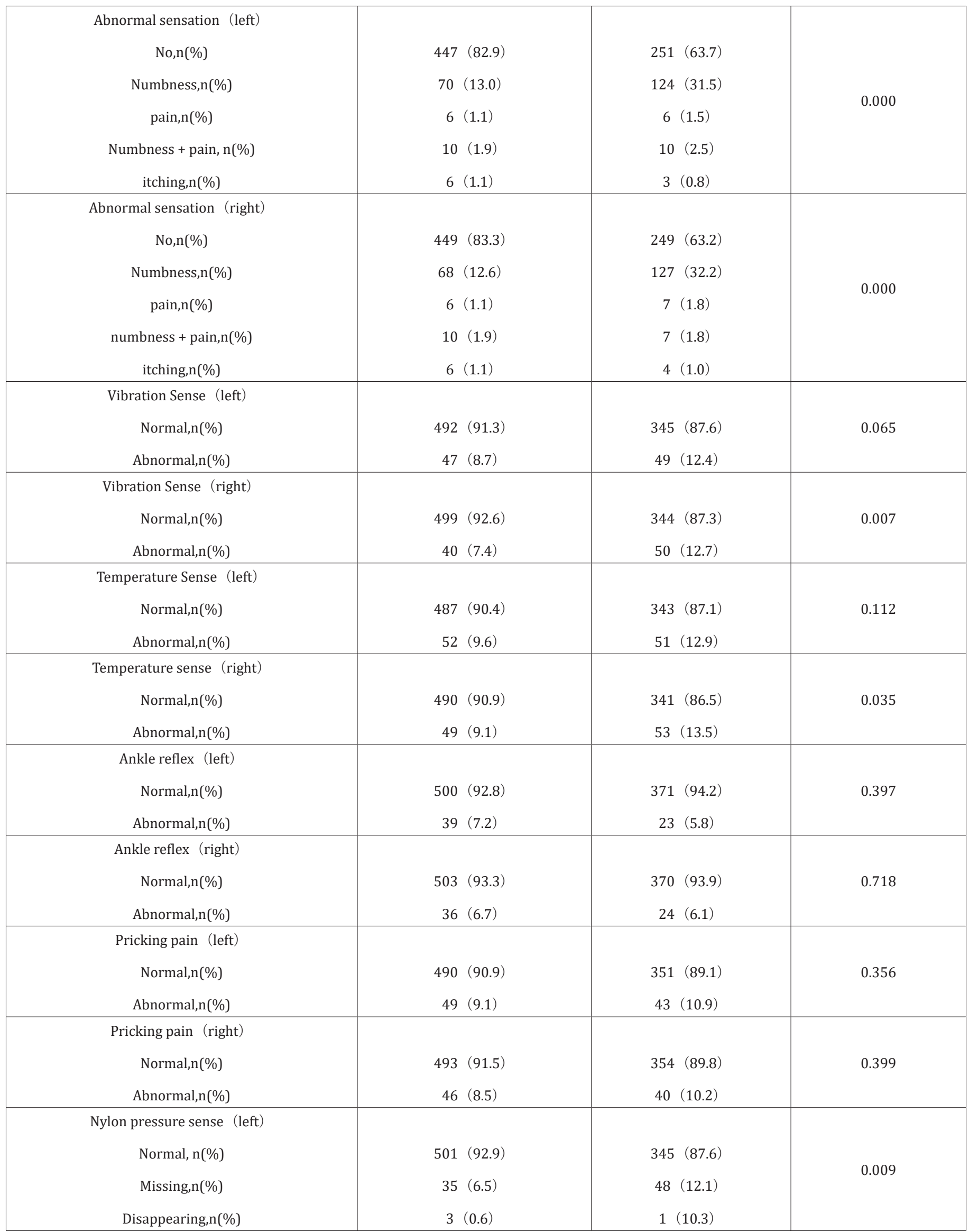




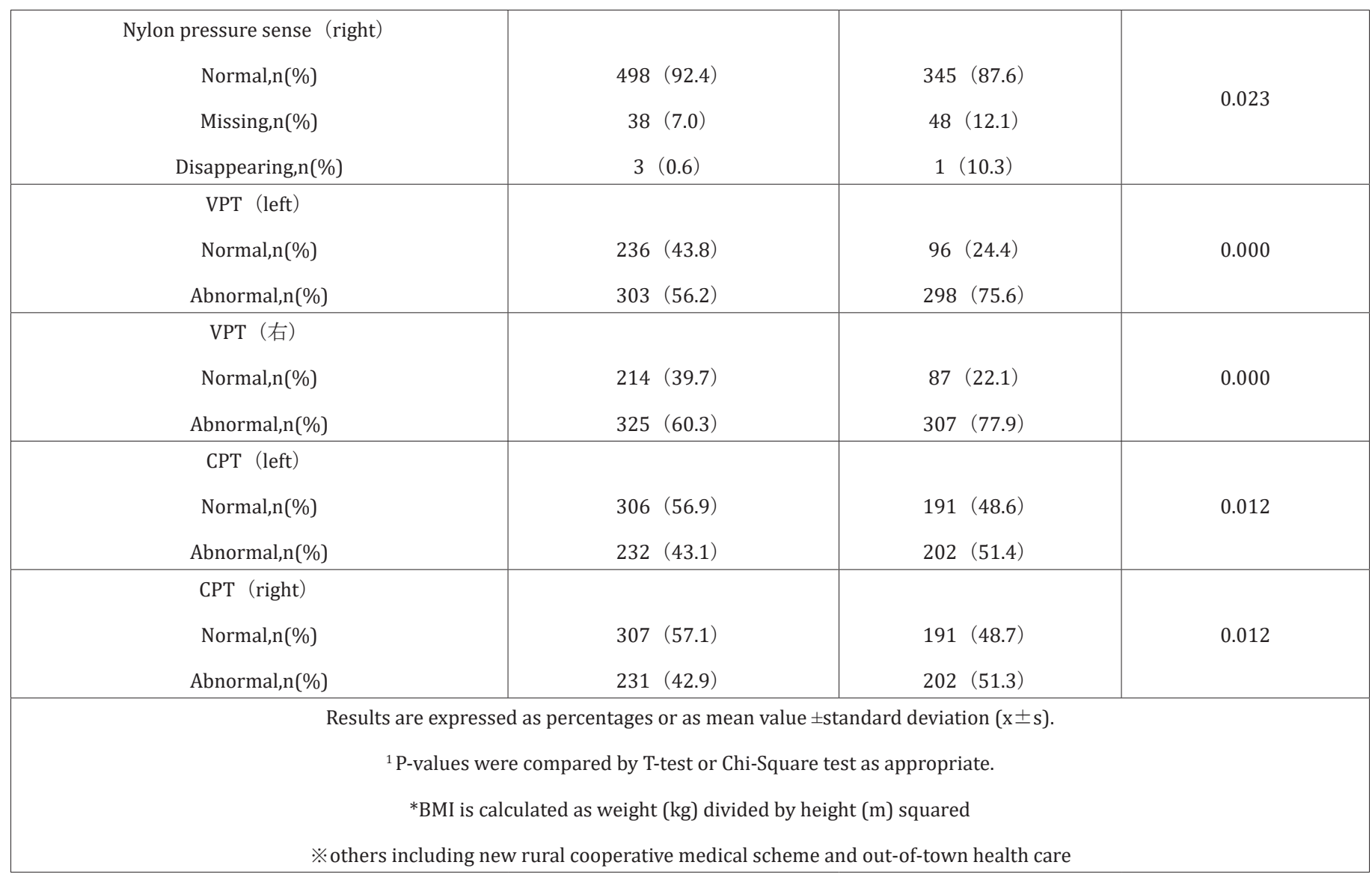

\section{Effect of Physical Exams or Tests on Diagnosis of DPN}

The five gold standard tests (Sense of touch, sense of vibration, temperature discrimination, tendon reflex) were recommended be propitious to predict early high risks, though VPT, CPT and Peripheral vascular diagnostic system or palpation of dorsal plantar artery or posterior tibial artery were also important to help diagnose DPN quantitatively. As shown in (Figure 4), if the test results of DPN and Non-DPN were listed in parallel, the four highest percentages of test results were put in order: VPT $>$ CPT $>$
Numbness > Pinpricking pain. However, if test results of DPN were subtracted by those of Non-DPN, the four highest test results were put in order: Numbness > VPT > Pinpricking pain > Sense of Nylon pressure (sense of touch disappearing) (Figure 5). Those four tests may be useful to alert clinicians to bear in mind and diagnose DPN earlier. Some factors were assumptive and deemed as keys in T2DM, like HbA1c, hyperlipidemia, FBG, but they were not as important as in DPN except hyperglycemia medication (Insulin + oral antidiabetic medications) (Table 2).

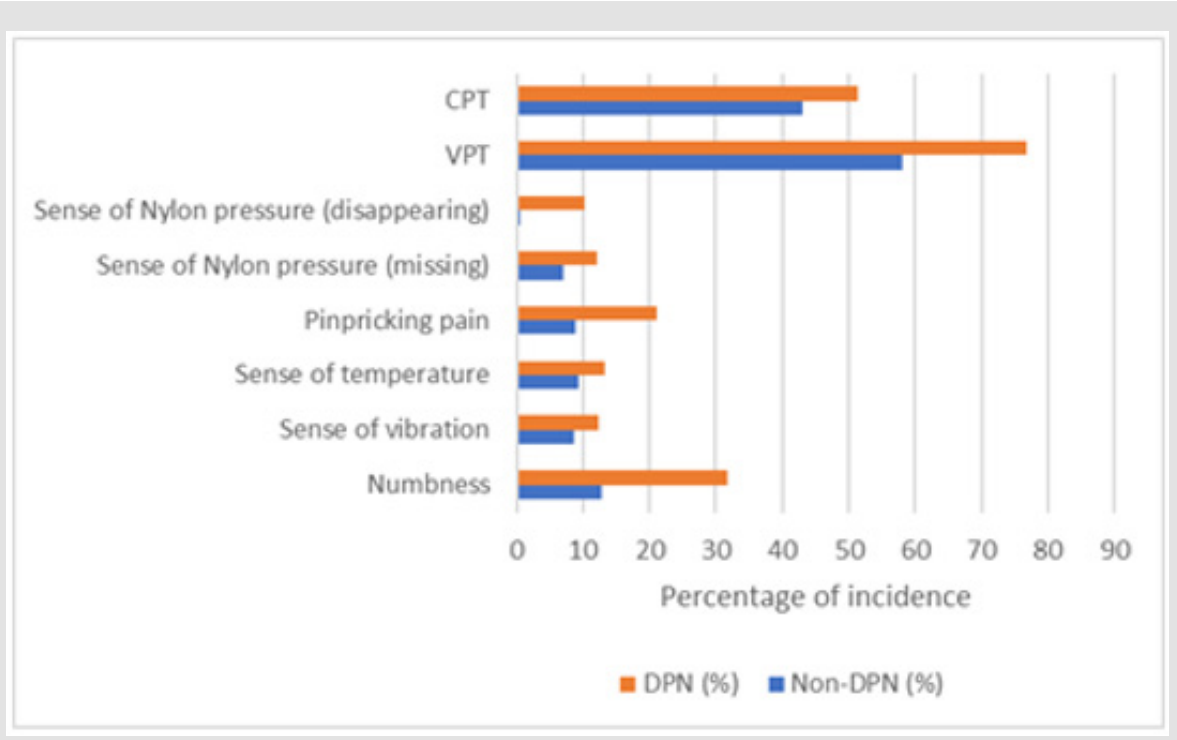

Figure 4: Comparison of risk factors by physical exams between DPN and Non-DPN ( $\mathrm{n}=933)$. 


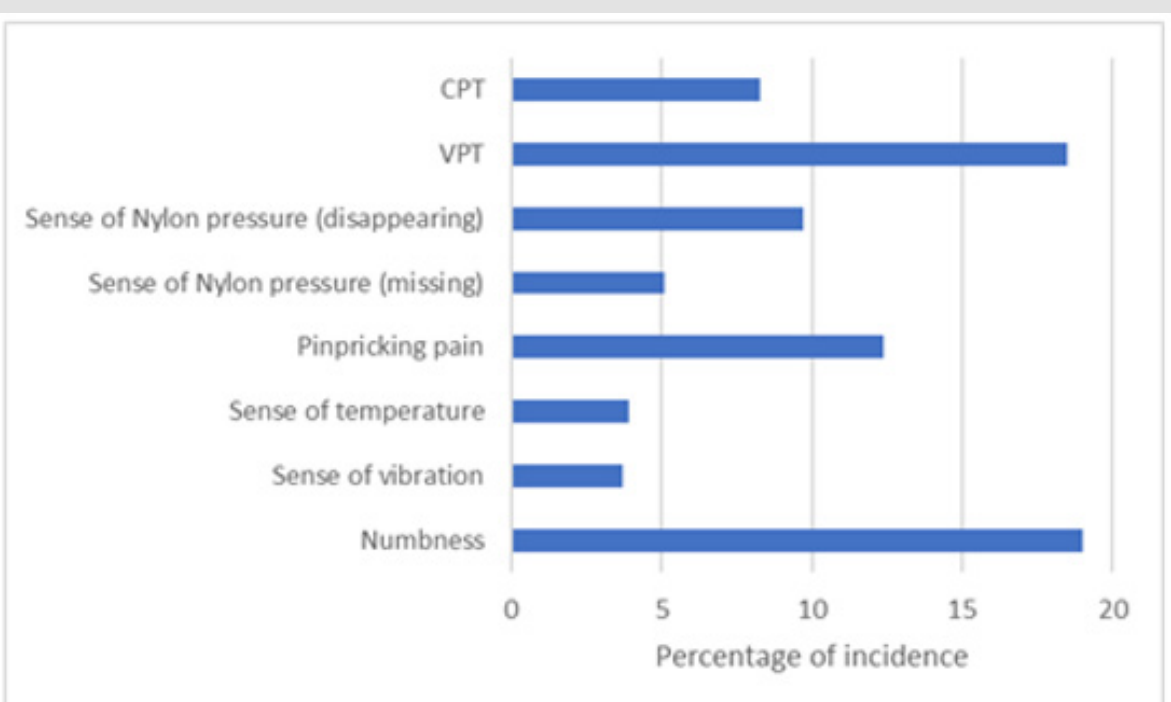

Figure 5: Net of risk factors through physical exams by DPN minus Non-DPN ( $n=933)$.

Table 2: Insignificant factors of Lab results between DPN and non-DPN. (n=933).

\begin{tabular}{|c|c|c|c|}
\hline Risks & Non-DPN $(n=539)$ & DPN (n=394) & $P$ value \\
\hline \multicolumn{4}{|l|}{ HbA1c（\%） } \\
\hline$<7, \mathrm{n}(\%)$ & $112(20.8)$ & $84(21.3)$ & \multirow[t]{2}{*}{0.841} \\
\hline$\geq 7, \mathrm{n}(\%)$ & $427 \quad(79.2)$ & $310(78.7)$ & \\
\hline $\mathrm{TC}(\mathrm{mmol} / \mathrm{L})$ & $4.80 \pm 1.38$ & $4.79 \pm 1.32$ & 0.977 \\
\hline $\mathrm{HDL}(\mathrm{mmol} / \mathrm{L})$ & $1.02 \pm 0.40$ & $1.01 \pm 0.28$ & 0.985 \\
\hline LDL $(\mathrm{mmol} / \mathrm{L})$ & $2.77 \pm 0.90$ & $2.78 \pm 0.96$ & 0.912 \\
\hline $\mathrm{TC}(\mathrm{mmol} / \mathrm{L})$ & $4.80 \pm 1.38$ & $4.79 \pm 1.32$ & 0.977 \\
\hline \multicolumn{4}{|l|}{ BMI* $\left(\mathrm{kg} / \mathrm{m}^{2}\right)$} \\
\hline$<18.5, \mathrm{n}(\%)$ & $21(3.9)$ & $12(3.1)$ & \multirow{4}{*}{0.912} \\
\hline $18.5-23.9, \mathrm{n}(\%)$ & $199(37.1)$ & $143(37.1)$ & \\
\hline $24-27.9, \mathrm{n}(\%)$ & $232(43.3)$ & $166(43.1)$ & \\
\hline$\geq 28, n(\%)$ & $84(15.7)$ & $64(16.1)$ & \\
\hline \multicolumn{4}{|l|}{ FBG $(\mathrm{mmol} / \mathrm{L})$} \\
\hline$<7, \mathrm{n}(\%)$ & $214 \quad(39.7)$ & $189(48.0)$ & \multirow{2}{*}{0.012} \\
\hline$\geq 7, \mathrm{n}(\%)$ & $325(60.3)$ & $205(52.0)$ & \\
\hline \multicolumn{4}{|l|}{ Hypoglycemic agent } \\
\hline No,n(\%) & $87(16.1)$ & $36(9.1)$ & \\
\hline Insulin,n(\%) & $50(9.3)$ & $28(7.1)$ & \\
\hline oral medication,n(\%) & $281(52.1)$ & $210(53.3)$ & \\
\hline insulin + oral medication, $\mathrm{n}(\%)$ & $121(22.4)$ & $120(30.5)$ & 0.001 \\
\hline
\end{tabular}

Prevailing Risk Factors in Predicting and Diagnosis of DPN

The single factor analysis with statistical significance was used as the independent variable, and the multiple factor nonconditional logistic regression analysis was performed with the peripheral neuropathy of diabetes as the dependent variable, and odds ratios (ORs) were obtained between the comparison groups of DPN and Non-DPN with 95\% confidence interval (CI). The results were illustrated in (Table 3 and Figure 6). The prevailing risk factors of percentages for DPN were ranked by order: clinical abnormal sensation $(25.2 \%)>$ sense of Nylon pressure $(10.3 \%)>$ pinpricking pain $(9.9 \%)>$ sense of vibration $(9.6 \%)>$ sense of temperature $>$ tendon reflex, which was in line with the analysis in (Figure 5). 


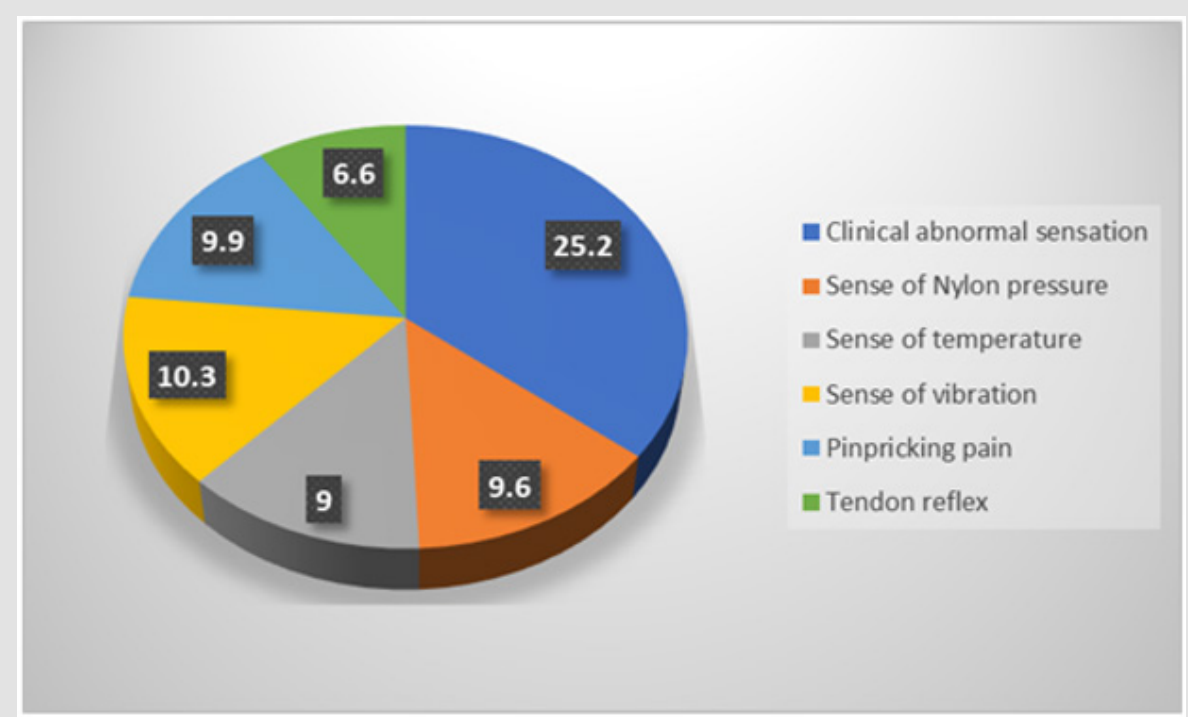

Figure 6: Prevailing risks of DPN by percentage $(\%)$. ( $n=933)$.

Table 3: Prevailing risk factors between DPN and non-DPN ( $n=933$ ).

\begin{tabular}{|c|c|c|c|}
\hline Parameter & OR & $95 \% \mathrm{CI}$ & $P$ \\
\hline Educational level & 0.805 & $0.682 \sim 0.950$ & 0.010 \\
\hline FBG & 0.974 & $0.945 \sim 1.004$ & 0.091 \\
\hline Diabetic retinopathy & 1.801 & 1.3202 .457 & 0.000 \\
\hline Diabetic angiopathy of lower extremity & 1.724 & 1.1732 .533 & 0.006 \\
\hline Callus (right) & 3.002 & 1.0019 .007 & 0.050 \\
\hline VPT(left) & 1.019 & $1.008 \sim 1.031$ & 0.001 \\
\hline Abnormal sensation(right) & 2.259 & 1.63 .120 & 0.000 \\
\hline Hypoglycemic agent & 1.301 & $1.031 \sim 1.642$ & 0.026 \\
\hline OR: Odds ratio, CI: Confidence interval. & & & \\
\hline
\end{tabular}

\section{Discussion}

With the increasing incidence of diabetes, the peripheral neuropathy of diabetes has been attracting more and more attention. However, the incidence of diabetic peripheral neuropathy varies from different studies due to different screening methods and standards. The prevalence of DPN was $42.2 \%$ in the present study, which was higher than the prevalence of $30 \%$ from a previous system review study [4,9-11]. The reason for such a difference might be ascribed to the difference by the diagnostic approaches and in different countries. However, a big variation of the prevalence of painful DPN from $35.7 \%$ to $65.3 \%$ was observed in the Middle East and North Africa region [12-14]. Among the 5 physical tests, the abnormal rate of temperature discrimination and vibration perception was higher than others. It suggests that we should pay attention to these two high risk factors from screening work. Among the clinical symptoms of DPN, pain received much more attention than necessary [13]. However, our results demonstrated that numbness accounted for the largest proportion of abnormal sense, and diabetic retinopathy held a great proportion as well, both which should drag people's attention and alert. Furthermore, if the patient complains of numbness, pain or itching of the lower limbs, he or she may have been troubling in the quality of life, pain disturbances, and decreased sleep quality [14-17]. As regards to patients without clinical symptoms, 24.4\% (170/698) patients had been diagnosed with DPN in this study.

It suggests that more details and attention should be paid to asymptomatic patients to reduce the rate of missed diagnosis of peripheral neuropathy. In our study, the risk of developing DPN increases with age and a longer history of the disease higher clinical symptoms of pain or numbness, and higher positive rates of VPT, CPT and nylon stress perception than patients without DPN, which is in line with previous reports [12,18]. Age is an independent risk factor for peripheral neuropathy [19]. It is widely believed that aging is driven by the accumulation of molecular and cellular damage in the body over time. As with peripheral neuropathy, both large and small fibers can be damaged by axonal injury or demyelization $[19,20]$. The high proportion of women in the DPN group compared to the non-DPN group suggests that women are more likely to develop DPN than men; this finding is consistent with previous studies [20]. In the level of education, the patients in the DPN group 
were mainly at middle school level or below, and the patients in the non-DNP group were mainly at middle school level or above. In medication, the proportion of DPN group was higher than that of non-DPN group in oral medication and Combined Control Regimen. Previous studies reported that patients treated with a combination of insulin and metformin who developed DPN were twice more than patients treated with metformin alone [14,21].

There were no significant differences in smoking and drinking between DPN and no DPN group, which is consistent with previous studies [19-24]. Higher Glycated hemoglobin strongly indicated that it is associated with DPN in T2DM, which might be considered as a reliable biomarker for screening for DPN [22].Kiyokazu et al suggested that hyperglycemia combined with dyslipidemia could induce mild peripheral motor and sensory nerve injury, but had no significant effect on sensory nerve conduction velocity [1]. In the literature, the risk of DNP was found to be associated with smoking [23]. However, the current study did not find the above coherence and association but was aligned with a previous study by Sendi et al [24]. The presence of Proteinuria, especially above 500 MGG, should alert clinicians to medicate or manage neuropathic pain in DPN patients [25]. Studies by Pan et al. have shown that retinopathy is an independent risk factor for DPN [26,27], and this conclusion has also been confirmed in our results.

DPN is the primary risk factor for the development of diabetic foot ulcers [28] and is implicated in $50-75 \%$ of no traumatic Amputations [29]. It is important to note that in general, foot loss of sensation is latent and could not felt by the patient in time. Patients with DPN often have larger shoe sizes, calluses, crevices, or skin changes [3]. The degree of pathological severity and clinical symptoms are often inconsistent and mismatched, and up to $50 \%$ of DPN patients remain asymptomatic [30]. In this study, there were about 43\% (170/394) of DPN patients who didn't have sensory abnormalities. Therefore, so early diagnosis of DPN presents a great challenge. The major problem with the development of DPN is that the process of pathogenesis is subtle and gradually progressed. Elder patients are inclined to be oblivious to the symptoms of pain, numbness or other paresthesia and take it for granted for old process [30,31]. Therefore, we should educate patients how to prevent diabetes from DPN.

\section{Conclusion}

The incidence of DPN and PAD in hospitalized patients was $42 \%$ and $5.6 \%$ respectively. Most of the patients with peripheral neuropathy are over 40 years old, prevailing risk factors including clinical abnormal sensation, abnormal sense of Nylon pressure, higher pinpricking pain, abnormal sense of vibration, loss sense of temperature discrimination, loss of tendon reflex, with longer than 10 years of diabetes, with diabetic retinopathy, kidney disease and lower limb vascular disease, accompanied by abnormal itching, numbness or pain, paresthesia without obvious cause. These higher risks should alert clinicians to reinforce the details in screening and take timely intervention in DPN.

\section{Acknowledgment}

This work was supported by Science Foundation of Guangdong Province of China (2016B010108008). We are indebted to Dr. Shang Zhi Xu (Ph.D., American Board of Toxicology, Rochester, Minnesota, USA) for proofing and reviewing the manuscript. The authors declare no conflict of interest.

\section{References}

1. Kiyokazu Ozaki, Yui Terayama, Matsuura T (2018) Effect of combined dyslipidemia and hyperglycemia on diabetic peripheral neuropathy in alloxan-induced diabetic WBN/Kob rats. J Toxicol Pathol 31: 125-133.

2. (2017) Diabetes society of Chinese medical association. Guidelines on prevention and treatment of type 2 diabetes in China (2017). Chinese journal of practical internal medicine 38(04): 292-344.

3. Barbosa M, Saavedra A, Severo M, Maier C, Carvalho D (2017) Validation and Reliability of the Portuguese Version of the Michigan Neuropathy Screening Instrument. Pain Practice: The Official Journal of World Institute of Pain 17(4): 514-521.

4. Juan Sun, Ya Wang, Xiaoyi Zhang, Shengze Zhua, Hong He (2019) Prevalence of peripheral neuropathy in patients with diabetes : A systematic review and meta-analysis. Primary Care Diabetes.

5. Miralles Garcia JM, De Pablos Velasco P, Cabrerizo L (2010) Sociedade Espanola de endocrinologia y Nutricion: Prevalence of distal diabetic polyneuropathy using quantitative sensory methods in population with diabetes of more than 10 years disease duration. Endocrinol Nutr 57: 414-420.

6. Bourcier ME, Ullal J, Parson HK (2006) Diabetic peripheral neuropathy: How reliable is a homemade 1-g monofilament for screening? Journal of Family Practice 55(6): 505-508.

7. Didangelos T, Zografou I, Iliadis F, Sambanis C (2019) Validation of Neuropad in the assessment of peripheral diabetic neuropathy in patients with Diabetes Mellitus versus the Michigan Neuropathy Screening Instrument, $10 \mathrm{~g}$ Monofilament application and Biothesiometer measurement. Current Vascular Pharmacology.

8. (2020) ADA. Standards of Medical Care in Diabetes-2020. Diabetes care 43(s1): 149.

9. (2019) Chinese Medical Association Diabetes Branch, Chinese Medical Association Infection Branch, Chinese Medical Association Tissue Repair and Regeneration Branch. Chinese guidelines for the prevention and treatment of diabetic foot, 2019 edition J. Chinese Journal of Diabetes 112: 92-108.

10. (2017) Chinese Society for the Promotion of international exchange of medical care and health, Diabetes Foot branch, Chinese guide to diagnosis and treatment of Diabetes Foot, Chinese Medical Journal 97(4): 251-258.

11. Liu X, Xu Y, An M, Zeng Q (2019) The risk factors for diabetic peripheral neuropathy: Ameta-analysis. PLoSONE 14(2): e0212574.

12. Wang DD, Bakhotmah BA, Hu FB, Alzahrani HA (2014) Prevalence and correlates of diabetic peripheral neuropathy in a Saudi Arabic population: A cross-sectional study. PLoS One 9: e106935.

13. Halawa MR, Karawagh A, Zeidan A, Mahmoud AE, Sakr M, et al. (2010) Prevalence of painful diabetic peripheral neuropathy among patients suffering from diabetes mellitus in Saudi Arabia. Curr Med Res Opin. 26: 337-343.

14. Elbarsha A, Hamedh MA, Elsaeiti M (2019) Prevalence and risk factors of diabetic peripheral neuropathy in patients with Type 2 diabetes mellitus. Ibnosina J Med Biomed 11: 25-28.

15. Lqbal Z, Azmi S, Yadav R, Jonathan Lim, Rayaz A. Malik, et al. (2018) Diabetic peripheral neuropathy: epidemiology, diagnosis, and pharmacotherapy. Clinical therapeutics 40(6): 828-849. 
16. Bredfeldt C, Altschuler A, Adams AS, Jennifer D Portz, Elizabeth A Bayliss, et al. (2015) Patient reported outcomes for diabetic peripheral neuropathy. Diabetes Complications 29(8): 1112-1118.

17. Pai YW, Lin CH, Lee IT (2018) Prevalence and biochemical risk factors of diabetic peripheral neuropathy with or without neuropathic pain in Taiwanese adults with type 2 diabetes mellitus. Diabetes Metab Syndr 12(2): 111-116.

18. Karki DB, Yadava SK, Pant S, Thusa N, Dangol E, et al. (2016) Prevalence of sensory neuropathy in type 2 diabetes mellitus and its correlation with duration of disease. Kathmandu Univ Med J (KUMJ) 14: 120-124.

19. Li Y, Lu B, Zheng H, Xiaona Qiao, Brian Lu, et al. (2019) Age as an Independent Risk Factor for Diabetic Peripheral Neuropathy in Chinese Patients with Type 2 Diabetes. Aging and disease 10(3): 592.

20. Abbott CA, Malik RA, Van Ross ER, Kulkarni J, Boulton AJ (2011) Prevalence and characteristics of painful diabetic neuropathy in a large community based diabetic population in the UK. Diabet Care 34: 2220-2224

21. Currie CJ, Poole CD, Evans M, Peters JR, Morgan CL (2013) Mortality and other important diabetes-related outcomes with insulin vs. other ant hyperglycemic therapies in type 2 diabetes. J Clin Endocrinol Metab 98: 668-677.

22. Su JB, Zhao LH, Zhang XL, Hong li Cai, Hai Yan Huang, et al. (2018) HbA1c variability and diabetic peripheral neuropathy in type 2 diabetic patients. Cardiovasc Diabetol 17(1): 47.

23. Hébert HL, Veluchamy A, Torrance N, Smith BH (2017) Risk factors for neuropathic pain in diabetes mellitus. Pain 158: 560.

24. Sendi RA, Mahrus AM, Saeed RM, Mohammed MA, Al Dubai SA (2020) Diabetic peripheral neuropathy among Saudi diabetic patients: A

ISSN: 2574-1241

DOI: $10.26717 / B J S T R .2020 .27 .004573$

Peiru Zhou, Jiaying Li. Biomed J Sci \& Tech Res

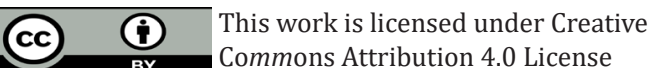

Submission Link: https://biomedres.us/submit-manuscript.php multicenter cross-sectional study at primary health care setting. J Family Med Prim Care 9: 197-201.

25. Pai YW, Lin CH, Lee IT, Chang MH (2018) Prevalence and biochemical risk factors of diabetic peripheral neuropathy with or without neuropathic pain in Taiwanese adults with type 2 diabetes mellitus. Diabetes Metab Syndr 12(2): 111-116.

26. Wu F, Jing Y, Tang X (2017) An independent risk factor of diabetic peripheral neuropathy in type 2 diabetic patients. Acta Diabetol 54: 925-931.

27. Pan Q Li Q Deng W, Dong Zhao, Hongmei Li, et al. (2018) Prevalence of and Risk Factors for Peripheral Neuropathy in Chinese Patients With Diabetes: A Multicenter Cross-Sectional Study. Front Endocrinol (Lausanne) 9:617.

28. Gogia S, Rao C (2017) Prevalence and risk factors for peripheral neuropathy among type 2 diabetes mellitus patients at a tertiary care hospital in coastal Karnataka. [J] 21(5): 665-669.

29. Ahlam A, Chamba N, Kayandabila J, Isaack A Lyaruu, Dekker Marieke, et al. (2019) Prevalence, Patterns, and Factors Associated with Peripheral Neuropathies among Diabetic Patients at Tertiary Hospital in the Kilimanjaro Region: Descriptive Cross-Sectional Study from NorthEastern Tanzania. International Journal of Endocrinology.

30. Jie FY, Zafar MI, Xu L, Raja Adeel Shafqat, Feng Gao, et al. (2018) Sensitivity of four simple methods to screen Chinese patients for diabetic peripheral neuropathy. Acta Endocrinologica (Buc) 14(3): 410-415.

31. Darivemula S, Nagoor K, Patan SK, Reddy NB, Deepthi CS (2019) Prevalence and its associated determinants of Diabetic Peripheral Neuropathy (DPN) in individuals having type-2 diabetes mellitus in Rural South India. Indian J Community Med 44: 88-91.

$\begin{array}{ll}\text { BIOMEDICAL } & \text { Assets of Publishing with us } \\ \text { RESEARCHES } & \text { - Global archiving of articles } \\ & \text { - Immediate, unrestricted online access } \\ & \text { - Rigorous Peer Review Process } \\ & \end{array}$

